\title{
A CREATION NARRATIVE FOR THE PSYCHOMETRIC SOCIETY AND PSYCHOMETRIKA: IN THE BEGINNING THERE WAS PAUL HORST
}

\author{
WILLEM HEISER \\ LEIDEN UNIVERSITY \\ LAWRENCE HUBERT \\ UNIVERSITY OF ILLINOIS
}

\begin{abstract}
A review is provided for the creation of the Psychometric Society in 1935, and the establishment of its journal, Psychometrika, in 1936. This document is part of the 80th anniversary celebration for Psychometrika's founding, held during the annual meeting of the Psychometric Society in July of 2016 in Asheville, NC.
\end{abstract}

Key words: blind reviewing, principal components, Journal of Educational Psychology, Psychometric Corporation.

There are four published sources available that can help develop a coherent account of the formation of the Psychometric Society (1935) and the founding of its journal, Psychometrika (1936):

(1) Dunlap, J. W. (1942). The Psychometric Society-Roots and powers. Psychometrika, 7, 1-8. Jack Dunlap was the sixth President of the Society; this was his Presidential Address (given September 4, 1941). Dunlap is considered one of the founding group of six: Jack Dunlap; Paul Horst; Albert Kurtz; Marion Richardson; John Stalnaker; and Leon Thurstone. In the 1930s and 1940s, Dunlap was a co-editor (for technical material) of the Journal of Educational Psychology (JEdP); rather surprisingly, JEdP was the only place to publish the type of quantitative work that Psychometrika would eventually solicit. As Dunlap states in the article listed below in (2) (1961, p. 66):

The speaker [Dunlap] was approached because of his knowledge and the volume of technical material available to him as editor of the Journal of Educational Psychology, the only outlet of consequence at that time for such articles.

(2) Dunlap, J. W. (1961). Psychometrics-A special case of the Brahman theory. Psychometrika, 26, 65-71. As part of the Society's twenty-fifth anniversary, the Chairman of the Program Committee for that year, Charles Wrigley, asked Jack Dunlap to review the early history of the organization and "discuss something of its achievements to date." This second paper is the result of that invitation.

(3) Horst, P., \& Stalnaker, J. (1986). Present at the birth. Psychometrika, 51, 3-6. The third published source we have for the founding of the Society and journal are actually notes drafted by Bert Green on the occasion of the fiftieth anniversary. Following the annual banquet for the Psychometric Society meeting at Vanderbilt in Nashville (organized by Bruce Bloxom, that year's President), Lyle Jones moderated a discussion with two of 
the living founders of the Society, Paul Horst and John Stalnaker. (One of the present authors ( $\mathrm{LH})$ was in attendance and remembers both this interesting after-dinner session, and the incredible 13-year cicada onslaught going on at the time.)

(4) Horst, P. (1983). Maximum utilization of human resources. This last piece was, in effect, a Horst "memoir" written for a conversation hour presentation at the APA convention in August of 1983. It was serialized in 1984/1985 over five issues of The Score: The Newsletter of the Division of Evaluation and Measurement (Division 5) of the American Psychological Association.

As noted in our subtitle, Paul Horst was the Prime Mover among the six Society founders; he began his crusade for a quantitative journal in the early 1930s (this was when Horst was still in his middle 20s; he started graduate study with Thurstone in 1927, receiving his Ph.D. in 1931. We might also remember that this was the difficult period of the Great Depression in the United States and elsewhere). Before joining the personnel group at Proctor and Gamble, Horst worked at the U.S. Civil Service Commission on measurement problems in industry before this particular position was eliminated as a result of the depression downturn (1930-32). One of his colleagues at the Commission was Albert Kurtz, who Horst enlisted in his quest. Kurtz became one of the six Society founders, and along with Horst, was one of the first (co-)editors of Psychometrika.

As a first attempt to obtain a quantitative journal, Horst attempted to buy one outright. And because $J E d P$ was the only outlet at the time for technical work in psychological measurement, he first tried that one. As Horst related (Horst and Stalnaker, 1986, p. 4; Horst, 1983, p. 13):

I began to consider the possibility of starting or buying a journal that would not only tolerate but welcome mathematically-oriented articles. The most likely prospect, it struck me, might be the Journal of Educational Psychology. I was making the lavish salary of thirty-two hundred dollars a year and, knowing nothing about the cost of publishing or the ownership of publications, it did not seem unreasonable that I could make a deal with the owner of Ed Psych. It was published by a Mr. Bucholz in Baltimore, only several hours drive from Washington. In those days we worked Saturday mornings, but on a Saturday afternoon I drove up to Baltimore to find $\mathrm{Mr}$. Bucholz. I located him in a sort of shed in the back of his home where, in an inkstained apron, he was apparently working on getting out an issue of the journal. I told him of my interest and asked whether he might consider selling the journal. He answered with an unequivocal "no" and turned back to his work, just as though I were no longer there-immediately after which I was not.

Some years later, I got to know Jack Dunlap who was then editor of Ed. Psych. He told me about a story related to him by Bucholz, the publisher. It seemed that some brash young squirt had wandered into his shop one time, pretending that he wanted to buy the journal. Naturally, it didn't take him long to get rid of the chap.

After being turned down in the purchase of $J E d P$, Horst and Kurtz set out in earnest to start a new journal devoted to work in quantitative psychology. It was Kurtz who proposed the establishment of a professional society, if only to have a group of captive journal subscribers. Kurtz also proposed charging libraries double the subscription rate with the offer of a second copy of the journal for binding. Once Horst and Kurtz had elicited Thurstone's enthusiastic support for the project (along with that of Chicago colleagues, Richardson and Stalnaker, and $J E d P$ editor, Dunlap), the "die was cast" (so to speak) with the formation of the Psychometric Society in 1935 and the first volume of Psychometrika appearing in 1936, with co-editors Horst and Kurtz, and managing editor Richardson. For the first officers of the Psychometric Society, we have Thurstone as President, Horst as Secretary, Dunlap as Treasurer, and Stalnaker as chairman of the membership committee. 
As Dunlap (1942, pp. 4-5) noted, "If the journal were to appear immediately, it was necessary that some legal unit be responsible for the financial arrangements. This was the basic reason for the formation of the Psychometric Corporation, independent of the Psychometric Society." This corporation was founded and incorporated in the State of Illinois in August of 1936. The initial members of the Psychometric Corporation were the six founders plus J. P. Guilford and Harold Gulliksen, all of whom had offered pledges of financial support. Gulliksen supported the journal despite the fact that he had reservations: "Harold Gulliksen tells me initially he opposed the idea of a new journal. He felt then as he does today that the need is not for more journals but for more good ideas worth publishing." (Horst \& Stalnaker, 1986, p. 5). The Psychometric Corporation remained in existence until the early 1960s when it was quietly absorbed into the Society itself.

To obtain a sense of purpose for the Psychometric Corporation as opposed to the Society, Dunlap (1961, p. 67) reports on a letter written to him by Thurstone in July of 1936:

We have been discussing the relation of Psychometrika to the Psychometric Society. It seems best to organize the Psychometric Corporation whose principal function would be to publish the Journal. Members of the corporation would be those who had made some contribution for its support. The principal reason why we suggest the Psychometric Corporation as the owner and publisher of the Journal is that the objectives of the Journal should be maintained. There is, of course, some possibility that the popular control of Psychometrika might change its character in a few years to a popular mental test Journal. This is, of course, not our principal objective and it seems best therefore to place the ownership and control of the editorial policies in the hands of the initial group with such additions as they may elect. Eventually we might have to make some compromises in the direction of popular mental test material, but such questions of policies should be in the hands of those who initiated and sponsored the Journal financially rather than in the hands of popular vote. This is what we have in the back of our minds in arranging for a partial separation in controlling the Journal.

In reviewing the four published sources for the Society and journal formation, there are a few additional items worth noting. One was the sceptism on the part of Horst and Kurtz about the objectivity of the more well-established professors in the field; we quote from Horst and Stalnaker (1986, p. 4):

Horst and Kurtz did not trust the objectivity of the well-established professors in the reviewing process. Kurtz suggested maintaining anonymity of authors of manuscripts during the reviewing process, now called "blind reviewing." The idea was to put the well-established professors on a par with the new, young contributors. Kurtz devised an elaborate rating sheet on which reviewers evaluated each manuscript. These policies are still in force, in some form.

We might add the historical observation that this process of "double-blinding," where the author(s) and reviewer(s) do not know each other's identity, may have been a first for any journal in psychology or the social sciences more broadly. Psychometrika and the Horst/Kurtz editorial team were truly ahead of their time in how manuscripts were to be processed based on merit and not merely on author reputation.

One of the current authors (LH) will argue in another venue that Harold Hotelling's seminal 1933 article in $J E d P$ that introduced Principal Components might have appeared in Psychometrika had the latter been around a few years earlier than it was. Horst related (Horst and Stalnaker, 1986, p. 5) how he tried to get something comparable for the first volume of Psychometrika: 
At Proctor \& Gamble we had been working with the applications of the new factor analytic methods to personnel data. I had learned of a new iterative procedure that Hotelling at Columbia had developed for finding the principal axis factors of a correlation matrix, and we were using it at Proctor \& Gamble. I saw Hotelling personally at Columbia during this time, to persuade him to contribute his manuscript for the maiden issue of Psychometrika. I asked him whether he could give us a manuscript on his new method. He at first was markedly cool to the idea and I suspected that he was not eager to conceal his production under the cover of a dubious new journal. I then told him that I very much wanted this method published in this first issue and that, if he did not feel he could do it, I would reluctantly publish the method myself and of course give him full credit. With this, he decided to provide the manuscript himself [Hotelling, H. (1936). Simplified calculation of principal components. Psychometrika, 1, 27-35], and we remained good friends as long as he lived.

When Thurstone threw his considerable support behind getting Pyschometrika up-andrunning, Horst and Kurtz gave him free hand in anything he was willing and interested in doing. One thing Thurstone offered was to design the cover for the journal, which he did. This gray cover for Psychometrika lasted until 1984 when the current blue cover was adopted. This change (engineered by Bert Green, then head of the Editorial Committee) was not universally appreciated, particularly because the Psychometrika motto was removed: "A journal devoted to the development of psychology as a quantitative rational science." Partially in protest of the cover change, a student of Norm Cliff (who was the editor of Psychometrika at the time), produced gray tee-shirts for sale bearing the old cover design. Legend has it that these tee-shirts could impart remarkable power to its wearers; one of these was for positive reviews for a manuscript submitted to Psychometrika if the shirt was worn when opening the old manila envelopes from the editor.

It is safe to conclude that Paul Horst was the major reason for the formation of both the Psychometric Society and its journal, Psychometrika. Even though this time period of creation coincided with the Great Depression, when money and jobs were very scarce, Horst as a young man in his twenties and not making a huge salary still offered to underwrite the losses of the journal for the first year for up to one-forth of its cost. This gesture on Horst's part assured the financial success of the endeavor, and prompted some ten other individuals to quickly offer their own financial help in the founding of the journal. According to Dunlap (1961, p. 67), all such loans were repaid by 1941 . Horst also served the journal editorially; he was an editor, co-editor, or managing editor for twenty of the first 30 years of Psychometrika's existence. For example, after serving as a founding co-editor (along with Kurtz) for the first 5 years of Psychometrika, he took on the task of managing editor for some 3 years thereafter and prior to his appointment during World War II as the United States Air Force's Chief for Selection and Training (1943-1945). As Horst put it (1983, p. 18):

From March 1940 through June of 1942, I assumed the managing editorship of Psychometrika. My wife and I conducted the operation in a basement room of our Cincinnati home, with the aid of an old second-hand ditto machine. Of course, the nitty-gritty, real work was done in those early years by the able assistant managing editor, Dorothy Adkins.

After receiving his $\mathrm{PhD}$ with Thurstone (in 1931), Horst functioned for some time as a wellpaid industrial psychologist for Proctor and Gamble. He was President of the Psychometric Society in 1941; Director of Research at ETS (1949-1950); and President of APA Division 5 (1951). In 1947 he joined the University of Washington, retiring at age 65 in 1969 (the mandated custom at the time). During his academic tenure at Washington, Horst continued to contribute mightily to the field of psychometrics generally and to the Psychometric Society and Psychometrika in 
particular. We might close with the mention of two remarkable books that Horst published in the 1960s: Matrix Algebra for Social Scientists (1963), and Factor Analysis of Data Matrices (1965). These two texts present comprehensive and elegant approaches to the analysis of a data matrix based on what Horst called the basic structure of a matrix. It might also be mentioned that although Horst introduced the concept of the basic structure of a matrix, it is derived in part from two seminal papers published somewhat earlier in Psychometrika: Eckart and Young (1936), The approximation of one matrix by another of lower rank; and Guttman (1944), General theory and methods for matric factoring (1944).

Paul Horst died on March 16, 1999 at the age of 95.

Manuscript Received: 3 OCT 2016

Published Online Date: 22 NOV 2016 